\section{EATING TERMS: WHAT THE CATEGORY REVEALS ABOUT THE THAI MIND}

\section{Unchalee Singnoi $^{1}$}

\begin{abstract}
The study surveys eating terms in Thai to find out complexities of the way the Thai people really categorize. It employs devices of a new view that takes more complex categorization as the main way in which we make sense of experience. That is, categories in this study are characterized depending on the bodily nature of the beings doing the categorizing, with imaginative mechanisms such as metaphor, metonymy, and mental imagery, on the one hand, and the theory of prototypes, on the other hand.
\end{abstract}

The findings show that there are a large number of terms (up to 43 words) used to express the sense 'to eat' in the Thai language. Such words form the eating category which is complex in nature. There is a small number of the category members inherently containing the eating sense. Others are used via idealized cognitive models like metonymy and metaphor. The category also shows the relationship among its members, where non-prototypical members are extended from the prototypical scenario in the form of radial structure. Furthermore, it is also found that the prototypical cases are in accordance with polite terms. The understanding of how the Thai people categorize eating as such is, we believe,

\footnotetext{
${ }^{1}$ Associate Professor, Faculty of Humanities, Naresuan University, Phitsanulok, Thailand.
}

central to any understanding of how they think and how they function and, therefore, central to an understanding of their mind.

\section{Introduction}

In order to understand individual things in the world, we have to understand them not only in terms of themselves but also as categories. This implies that the words of a language can be understood via the concept of categorization rather than only in terms of individual words. In the classical view (i.e., the objectivist view) categories are based on shared properties. Recent theories of categorization are far more complex than that.

Dictionaries, for instance, provide no clear differences between words with similar meanings and are not concerned with semantic shifts. In fact, they are said to be "frozen pantomime" (Bolinger 1965). Haiman (1980) agrees that true dictionaries are not concerned with cultural knowledge. They only deal with cognitive meaning rather than cultural and experiential meaning.

Accordingly, Lakoff (1987) points out that dictionaries provide definitional knowledge in terms of the classical view in which cognition is based on a metaphysical account of a reality made up of objectively existing entities with inherent properties and with relations among them. Some properties are essential and other are not. Definitional knowledge is knowledge of the essential properties of words. Therefore, the words of a language are defined according to the essential properties of the entities and categories that the words designate. This means that figurative expressions such as metaphors, metonymies, and mental 
images, which do not have meanings that can directly fit the real in this ways could not be part of the definitions. In the traditional view, these imaginative aspects of reason are taken as peripheral and inconsequential adjuncts to the literal.

In the area of Thai semantic studies, recognition of the limitations of dictionaries has given rise to a number of significant pieces of work in semantic categorization. One of them is the study of 'cutting terms' by Suwilai Premsrirat (1983) which elaborates in great detail the categorization of the concept studied. This work is an exhaustive survey of cutting terms in Thai and an attempt to provide fine definitions for these terms by sorting through semantic elements of cutting words and grouping them by a variety of discrete features such as instruments used, kinds or texture of objects to be cut, cutting manners, and goal shapes of objects. The study made a significant contribution to the semantic study of Thai since it provided not only a nice lexical set but also a particular view of cutting activities with the use of various cutting tools that reflects part of Thai culture. However, the study still has a drawback in that it lacks any illustration of the nature of categories that involve not only human experience but also the way people use their imaginative aspects, the new view, which is believed to provide increased insight into the nature of the language.

In the new view, i.e., experientialism, categories show that the way people categorize things is far more complex than the classical view in which categories are merely based on the shared properties of their members. ${ }^{2}$ The foundation of the new view of categorization is the work of Eleanor Rosch on categorization called "prototype theory". The approach to prototype theory that I am presenting here suggests that human categorization is essentially a matter of both human experience and imagination-of perception, motor activity, and culture, on the one hand, and of metaphor, metonymy, and mental imagery, on the other.

In the new view those "figurative" aspects of categorization should be viewed as central to reason. Definitions of the words in a language should make use of those aspects centrally. This means that definitions are made relative to "idealized cognitive models" or ICMs proposed by Lakoff (1987), the structures by means of which we organize our knowledge. An ICM is a complex structured whole which makes use of structuring principles of propositional structure, image-schematic structure, metaphoric mappings, and metonymic mappings. It is the organization which is the source of category structures and prototype effects. Lakoff takes the English word Tuesday as an example. Tuesday can be defined only relative to an ICM that includes the natural cycle defined by the movement of the sun. A larger seven-day calendric cycle is the week. In the ICM, the week is a whole with seven parts organized in a linear sequence; each part is called a day, and the third is Tuesday. The concept of a week is idealized; it does not exist objectively in nature. They are created by

\footnotetext{
2 See Lakoff (1987) for some sense of the development of the major ideas of categorization.
} 
human beings, and not all cultures have the same kinds of week.

Thai has a large number of 'eating' expressions that include different terms for eating in particular ways or manners, for eating different kinds of food, for eating with different instruments, for different kinds of eaters, and for eating in different social situations. This includes terms that express other actions, like 'hitting' and 'stuffing' or certain parts of the eating process, like 'digesting' (in the mouth) or 'swallowing'. This is not simply a matter of categorization by shared properties. The way the category of eating is organized is not merely as a set of similar properties, but also as an ICM, incorporating, at least, metaphoric and metonymic mappings.

The aim of the present study, therefore, is to perform a semantic analysis of the category of eating in the standard Thai language from an experientialist view. This is a case study, showing that the range of ways that Thais can use to refer to eating can be explained in terms of the prototype theory. In particular, we attempt to isolate a prototype and its properties, to give a linear ranking of how close nonprototypical cases are, to provide an account of the details of the cognitive models that give rise to the representative structure of the eating category, to find how metaphoric and metonymic models are made use of in talking about eating, and to see how cultural knowledge is organized in terms of ideal eating, which leads to prototypical effects.

\section{Problems with the definition of 'Eating'}

As traditionally defined by dictionaries, e.g., the Standard Thai Dictionary (Royal
Academy of Thailand, 1999) and the Collins cobuild English Language Dictionary (Collins Birmingham University International Language Database, 1992), 'eating' refers to the action of getting food into the body; that is, when one eats something, one first puts food into one's mouth, chews it, and then swallows it.

The conceptual category of 'eating' in Thai culture is represented by a large number of words some of which cannot be defined as being able to indicate eating in any Thai dictionaries. Therefore, a number of questions still need to be addressed. Why are certain words still used to refer to the entire eating action even though they do not entail the whole eating process? Why are the certain number of words that express other actions like 'stuffing', 'hitting', 'getting rid of', 'obtaining', etc. used to express particular ways of eating, and how do we know and make use of them? How do we conceptualize those sets of expression as eating actions? Since the source of definitions as such cannot provide us further accounts or insights than literal meanings of expressions that occur in large text corpora, it is worth working on a semantic analysis of the eating category in Thai to provide adequate accounts for eating expressions that go beyond those of dictionaries.

\section{Folk theory}

Let us begin our investigation with the ICM that people have for the aspect of eating, say, the common folk theory of the physiological activities of eating. In general, the concept of eating physiologically requires a simple notion as: 
When we eat, we put food into our mouth, we chew it, and then we swallow it.

We could rewrite the folk theory in terms of a process of eating consisting of at least three actual steps:

\section{PUTTING FOOD INTO THE MOUTH}

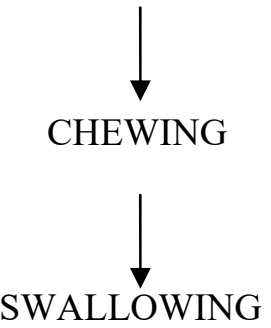

Figure 1: Basic Process of Eating

In fact, it should be noted that not all the steps are necessary conditions for eating. Sometimes we put food into the mouth and swallow it without chewing, depending on the kind of food or what we are eating. Take kin yaa 'take a tablet', for example. However, we do not count activities that are limited to either the first step or the last step as eating. The two steps, PUTTING FOOD INTO THE MOUTH and SWALLOWING IT, therefore, are necessary conditions in performing the eating action.

It is interesting that a contradiction to this basic eating process is found when we take a closer look at terms used for eating in Thai. I found that there are quite a number of words originally related to only certain steps of the eating action. There, thus, emerges a pattern of lexical extensions from this folk model using metonymy.

\section{Metonymy}

Metonymy is one of the basic characteristics of cognition. According to Lakoff (1987), it is the case that salient part or aspect is commonly used to stand for the things as a whole or for some other aspects or part of it. A large number of 'eating' words in Thai indicate eating metonymically. In doing this, the Thais make use of one or more steps of the basic eating process presented above to stand for the whole process.

\section{Words of two steps: 'putting food into the mouth' and 'swallowing it' as eating}

There are a number of words denoting only the first and last steps of eating, PUTTING FOOD INTO THE MOUTH and SWALLOWING IT, in the basic model given. These two steps stand for the whole eating process where the two actions are prominent. In other words, they picture a particular eating manner, 'eating without chewing'. We do sometimes eat food in different abnormal ways depending on circumstances involving kinds of food, paces, and manners of eating. This group of words denoting 'drinking', 'sipping', and 'slurping', is used for the concept of eating certain sorts of food like soup or other liquid food with no chewing, as shown in the examples below.

- ดื่ม $d 1(1 \mu$

Source: 'to drink'

$d 1(1 \mu$ nom

eat milk

'Drink milk.' 
- จิบ

$c i l p$

Source: 'to sip'

cilp thii la/? nOlOy

sip Clf Part a little bit

'Eat a little bit at a time'.

- ซด so/t

Source: 'to slurp along with an amount of air, thus making a noise'

yala so/t na/am mol $t$

don't eat water all gone

'Don't eat up its juice.'

\section{Words of one step: 'putting food} into the mouth' as eating

Sometimes we use words which convey the sense referring to only the first step of eating, PUTTING FOOD INTO THE MOUTH, to stand for the whole eating process since this sense is the most salient in the eating process of the basic model. The largest number of words are found characterizing different ways of putting the food into the mouth: 'putting', 'stuffing', 'grabbing', 'sucking', 'licking', etc. Each characteristic may be further shaded into different sub-characteristics regarding instrument, aspects of food, paces, and manners. Examples are shown below.

$$
\text { - เปิบ } \quad p \cong(\cong p
$$

Source: 'to put food into the mouth with all five fingers'

$p \cong(\cong p \quad$ kha law $t\{$ llal? kham $\quad s\{<\{n$ lambalak

Eat rice each bite very hard

'Eating rice each bite is very hard.'

$$
\text { - โซ้ย So/oy }
$$

Source: 'to put food into the mouth by chopsticks'
pay so/oy
kha /awto/m kan
go eat
rice soup together

'Let's go eat rice soup together.'

$$
\text { - ฮุบ } h u / p
$$

Source: 'to grab a chunk of food like fish'

$h u / p \quad k h a / w$ pay $l\{l\{w$

eat enter go already

'(Someone) eats a chunk of food rapidly like a fish.'

- ดูด du(ut
Source: 'to suck'
$d u(u t \quad$ nom
eat milk
'Drinking milk'

- เลีย lia

Source: 'to lick'

lia ?aytim

eat ice cream

'Eating ice cream'

- แทะ th\{ $\{$ \{?

Source: 'to gnaw'

th $\{$ \{ $\{$ ? kradu $(u k$

eat bone

'Eat bones'

\section{Words of one step: 'chewing' as eating}

When we eat something which we have to chew for a longer time than when we normally eat, we then use a 'chewing' word to stand for the whole eating process. The chewing step is salient in that particular eating. An example is:

- เคี้ยว

khilaw

Source: 'to chew'

khi/aw mi laN

eat tea leaves

'Eating tea leaves'

Instead of chewing, sometimes we digest food by dissolving it in the mouth. Therefore, it denotes a particular characteristic of eating: 
- อม ?om

Source: 'to dissolve food in the mouth in stead of chewing'

?om lu $/ u k$ ?om

eat candy

'Eating a candy'

\section{Words of one step: 'swallowing' as eating}

A number of words denoting SWALLOWING FOOD can also stand for the entire eating action when this step is salient. Excepting the work, $k l 11 n$, that indicates swallowing food in a normal way, there are a number of swallowing words representing abnormal eating actions. Examples of illustrative cases are:

- กระเดือก $k r a d 1 l a k$

Source: 'to swallow with difficulty' ?aaha<an ma/y ?arOly krad1lak ma/y loN

Food not tasty eat not down 'The food is not that tasty, (I) can't eat (it).'

- ขยอก khay $\mathrm{O} / \mathrm{Ok}$

Source: 'to swallow a big chunk slowly with difficultly like a snake'

khayO/Ok kha/w pay da/y thudiaw tha/N?an

Eat enter go able a time whole 'Someone has eaten up a big chunk of food at one time.'

As has been discussed, each target word above indicates the eating via its capacity to stand for the whole event while keeping its particular inherent characteristic along with the metonymic function. Their particular characteristics are presented in the last parts of the given definitions.

\section{Metaphor}

So far, we have seen that metonymies can provide motivation for the extension of the 'eating' category. Another important kind of motivation comes from another conventional mental image, metaphor. Metaphor in the sense of cognitive linguistics theory like Lakoff and Johnson (1980) is conceptual, not merely the usage of language. It involves with people's world view and thought in a social system. Metaphorical models thus are culturally heuristics. They help us understand some things in terms of others that we already understand.

\section{Principal metaphor}

With regard to the folk theory of eating, both of the two necessary steps, PUTTING FOOD INTO THE MOUTH and SWALLOWING FOOD, give rise to the concept 'eating is putting food into the body'. This means that we understand our own bodies as a CONTAINER. We have a container as an image schema that has a boundary distinguishing an interior from an exterior. (In fact, eating is only one experience we understand in container terms; according to Lakoff and Johnson (1980), there are numerous experiences in our daily life that are understood via this image schema, e.g. , breathing in or out, going in or out, putting in or out, and so on.) The examples below show our comprehension of eating in container terms:

kin tem thi $/ i$

'Eating fully so that you can't eat any more'. 
kin sal? yala haly th/O/ON

wa $/ \alpha N$

eat Part don't let stomach empty

'Eat. Don't let your stomach be empty'.

kin con lón krapqO/?

eat until overflow bladder

'Someone eats too much.'

tha la ma/y kin $\kappa O / O$ khaay ?OlOk maa

if not eat then spit out

'It you don't want to eat it, spit it out.'

ha<a khO<ONkin saly kraphO/?

find thing-eat put into stomach

'Find something to eat.'

We have seen that the words like 'space', 'full', 'empty', 'over flow', 'spit out', and 'put in' demonstrate that the body is conceived in relation to a container, having a space that something is put into and ejected out of. A body is full when it is filled with food, and it is empty when nothing is put inside.

Therefore, we could say that the imageschema, container, gives rise to a principal metaphor EATING IS PUTTING SOMETHING INTO A CONTAINER. In this metaphor, the source domain is 'putting something into a container', and the target domain is 'eating'. Consequently, it is not surprising that we also make use of certain terms that originally meant 'stuffing something into a container', like $y a / t, d\{(\{k$, and krasu lak to express particular ways of 'eating'

The terms $y a / t, d\{(\{k$, and krasu /ak share the original semantic domain of 'stuffing something in a bag-like utensil'. The term $y a / t$ is differentiated from $d\left\{\left\{_{\{k}\right.\right.$ and krasulak by the different kinds of instruments employed; hands and a tool like a long stick, respectively. It is likely that the term $d\{\{k$ differs from krasu lak in the way that the former involves less force than the latter. When these three words are used to express eating, they represent not only the eating domain but also the characteristics of the original domain which can be depicted as 'eating too much food, as if there were someone stuffing food into one's mouth'. These expressions are also examples of metonymy (under the first step) since they have a part-whole relationship with the idealized model of eating. They, therefore, express eating via a combination of metaphor and metonymy, in which the behavior metaphorically corresponds to the three eating steps, which in turn metonymically stands for the whole eating action.

\section{Motivated metaphors}

The priority metaphor EATING IS PUTTING SOMETHING INTO A CONTAINER is fairly productive, it motivates, or provides sense to, other conceptual metaphors. It is likely that another metaphor is evoked via the idea that "putting something into a container is to make it disappear, get rid of it, or to finish with it'. The principle metaphor, thus, gives rise to another metaphor, say, EATING IS GETTING RID OF SOMETHING. The source domain of the metaphor is 'getting rid of something', and the target domain is 'eating'. It, thus, is not surprising that we make use of verbal expressions like 'getting rid of', 'finishing', and 'sweeping off' to express eating in particular given contexts. The expressions as such produce a picture of 
'eating up'. Consider the examples below where such expressions metaphorically indicate eating.

$$
\text { - กำจัด kamcal } t
$$

Source: 'to chase, to get rid of'

?aaha<an thi $/ i \quad l 1<a \quad$ cha<n kamcal $t$
rilap

food that left I eat up all gone

'I ate up the food that was left over.'

$$
\text { - จัดการ caltkaan }
$$

Source: 'to manage'

?aaha<an thi $/$ i $l 1<a \quad$ cha<n caltkaan

ri lap

food that left I eat up all gone

'I ate up the food that was left over.'

- กวาด kwalat

Source: 'to sweep off'

?aaha<an thi/i $\quad$ ll<a $\quad$ cha<n kwalat ri lap

food that left I eat up all gone

'I ate up the food that was left over.'

The metaphor also extends to the idea of 'getting rid of something partially' like 'trimming'. This expression when used in the eating category gives the picture of 'eating food slowly bit by bit' as if someone is trimming a brush.

\section{- เล็ม lem}

Source: 'to trim'

Mua lem yulu da/y kin rewrew keep eat bit by bit stay Part eat quickly 'Why do you still keep eating bit by bit? Hurry up.'

Let us get back to the metaphor EATING IS GETTING RID OF SOMETHING. It further motivates another entailment by extending to the concept 'getting rid of something by hitting it and therefore causing damage'. Therefore, we have
EATING IS HITTING SOMETHING as another metaphor where the source domain is 'hitting something' and the target domain is 'eating'. This could be a good reason why we include certain 'hitting' words in expressing eating. These terms give the picture of "eating everything up rapidly as if something were hit and knocked down and then were not in its original shape'.

$$
\text { - ซัด } s a / t
$$

Source: 'to hit things strongly like waves when hitting the shore'

mii tha/wraly salt rilap have that much eat up all gone

'No matter how much food was there, you ate it up.'

$$
\text { - ฟาด } \quad f a / a t
$$

Source: 'to hit something with a long flexible thing like a whip'

falat khalaw si<a sa<am caan eat up rice Part 3 plate

'(I) have eaten up 3 plates of rice.'

$$
\text { - ฟัด } f a / t
$$

Source: 'to fight like dogs, to hit' mii tha /wraly fa<t rilap have that much eat up all gone 'No matter how much food is there, you ate it up.'

Moreover, the metaphor EATING IS HITTING SOMETHING is likely to make further sense of the idea 'being in a distorted shape' in the way that, when something is hit, it is normally damaged or in bad shape. Therefore, it is possible that there arises another metaphor, EATING IS DAMAGING SOMETHING, where the source domain is 'damaging' and the target domain is 'eating'. When a word carrying the sense 'damaging something' is metaphorically made use of for eating, it 
indicates 'eating from inside or only picking something from the dish and thus damaging the food'.

- ฟอน

fOOn

Source: 'to damage, to make thing be in a bad shape'

yala foOn ?aw t\{ $\left\{\begin{array}{l}\text { m } m u<u \\ \text { d }\end{array}\right.$

don't eat from inside pick only pork,

kin pha/k dulay

eat vegetable together.

'Don't eat (by picking) only pork; eat the vegetable, too.'

So far, we have the view of how we have got the metaphoric expressions based on the principle metaphor EATING IS PUTTING SOMETHING INTO A CONTAINER. Motivated by this basic concept, eating is viewed as 'making something disappear out of sight' as presented by the words denoting 'get rid of it' or 'knock it down' above. When we knock something down, it is then ruined. From this point of view, we recognize ourselves being at the source point of the moving object from outside to inside. That is, we consider ourselves as 'agents' of the eating action. Based on the trajectory of the moving object, we also perceive eating by recognizing ourselves as being at the destination point of the moving object, which is in the container. This means we consider ourselves as 'recipients' of the eating action. This is more likely to be the answer to why we have certain eating terms originally carrying the sense 'getting or obtaining something'. The principle metaphor, therefore, could be said to motivate another metaphor, EATING IS GETTING SOMETHING, where the source domain is 'getting something' and the target domain is 'eating'. We make use of a number of words originating in this sense to indicate the eating action politely, as shown in the example below.

- รับ $\quad \mathrm{ra} / \mathrm{p}$

Source: 'to get'

pO/O cal? ralp kha/w ?ilik maly khal?

father will eat rice more Qest Part

'Father, would you like to eat some more?'

Moreover, there exists another term carrying the concept 'tempting or deceiving' which we could use to express eating. A possible explanation for this case is that it could be linked to the previous metaphor EATING IS GETTING SOMETHING. This metaphor motivates the idea that 'someone might take something because of temptation rather than for a good reason'. The metaphor, therefore, gives rise to another one, EATING IS TEMPTATION, where the source domain is 'temptation' and the target domain is 'eating'. When this term is used in the eating concept, it gives the sense of 'overeating'.

- ล่อ $\quad l O / O$

Source: 'to tempt'

lO/O ku<ati<aw kha/w pay ta/N

sa<am chaam

eat noodles enter go up to 3 bowl

'(I) have eaten up all three bowls of noodles.'

In short, the folk theory of eating forms the basis of the most general metaphor for the eating action. The principal metaphor motivates the other two different 
metaphors each of which further gives rise to another, which gives rise to another, and so on by chaining, as tentatively shown in the schema below. greedily, and snakes gradually swallow it. The terms we metaphorically make use with humans to indicate animal-like eating behaviors include $h u / p$ and kham 1 (op, for fish, khama/m, for dogs, sawa<opaam, for monkeys, and $k a y O / O k$, for snakes, as already given in their definitions in the section on metonymy above. The reason why the expressions

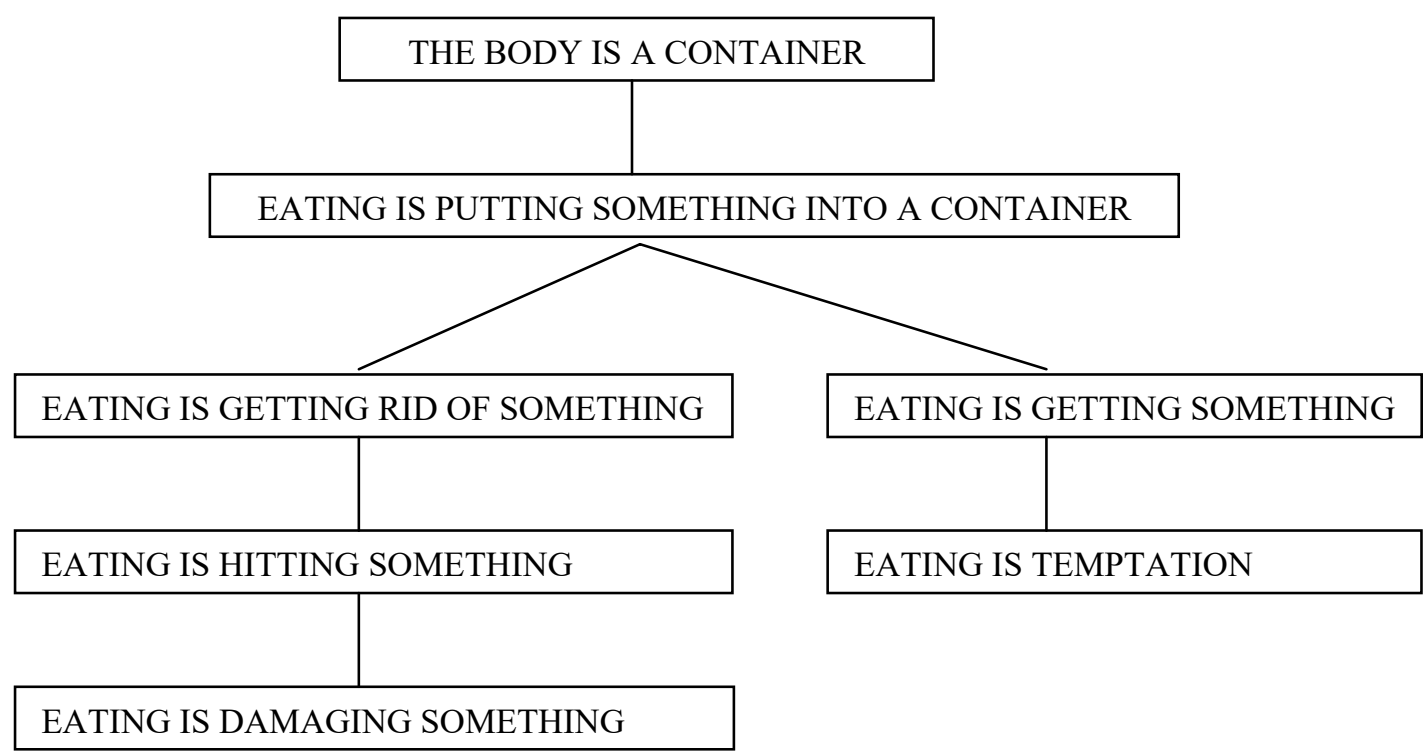

Figure 2: Metaphors in the Chaining Model

\section{Other metaphors}

In addition to the motivated metaphors, Thai people also metaphorically make use of animal eating actions and other actions that involve activities of the mouth to indicate eating in other certain particular ways. There are a number of eating terms which originally indicate particular eating behaviors of certain kinds of animals, like fish, dogs, monkeys, and snakes. When eating, fish and dogs snap a piece of food, monkeys use their hands to grab food are also cited in metonymy is that they, as parts, represent the whole eating process. Thus, they constitute particular cases that express eating via a combination of metaphor and metonymy.

\section{Prototypical scenario}

So far, we have seen that metonymy, metaphors and image-schema transformation can provide motivation for the extension of the eating category. Let us turn to a case involving the way in 
which these senses are extended using the prototypical scenario.

The term "prototypical scenario" as employed by Lakoff (1987) refers to a prototypical cognitive model that has a temporal dimension and can be conceived of as a scenario with a number of stages. We would employ this terminology in discussing our eating category. To discuss the prototypical scenario, we make use of the folk theory as the basic schema and extend it to match the social stereotypical concept of eating in the Thai culture, as shown below.

\section{STAGE 1: PUTTING FOOD INTO THE MOUTH}

The Thai people, at present, normally eat rice with a spoon and fork or, at least, with a spoon. We are supposed to put the food into our mouths in a polite way: at a normal pace, not too slowly or rapidly, and without making any noise. Each bite should not be too small or too big.

\section{STAGE 2: CHEWING THE FOOD}

We are supposed to chew the food until it is fine.

\section{STAGE 3: SWALLOWING THE FOOD}

We swallow the finely-chewed food without difficulty.

\section{STAGE 4: FINISHING}

We finish eating after we have eaten enough food, not too much, even though there is some food left.

From the prototypical scenario, we can pick out the features that characterize the prototype of eating for the purpose that they help our work to be more obviously seen in showing non- prototypical cases and how they are related to the prototype. The required elements include kinds of food, size of bite, instrumental usage, activity, pace of activity, and effort of activity, some of which can be further sorted out as presented below.

Elements of the Prototype of Eating

Kinds of food: solid food enough food

Size of bite: a tablespoon size

Instrument: spoon

Activities: putting food into the mouth chewing making no noise swallowing

Pace of activities: slowly

Effort of activities: without difficulty

Having the principal model (the folk model) and the elements above, we can restate the prototypical scenario in terms that will facilitate illustrating how varieties of eating deviate from the prototype. This will also show the relationship among those variants. The prototypical scenario can be simply restated as:

\section{STAGE 1: PUTTING FOOD INTO THE MOUTH}

We put food into the mouth.

The instrument is a spoon. 


\begin{tabular}{|c|c|}
\hline Prototypical & Non-prototypical \\
\hline $\begin{array}{l}\text { กวาด } k w a l a t \\
\text { STAGE 4: } \quad \text { enough food }\end{array}$ & eating up \\
\hline $\begin{array}{ll}\text { กระซวก } & \text { krasu } / a k \\
\text { STAGE 1: } & \text { slowly } \\
\text { STAGE 2: } & \text { slowly } \\
\text { STAGE 4: } & \text { enough food }\end{array}$ & $\begin{array}{l}\text { rapidly } \\
\text { rapidly } \\
\text { too much food }\end{array}$ \\
\hline $\begin{array}{ll}\text { กระเดือก } & \text { krad 1 }(a k \\
\text { STAGE 2: } & \text { chewing } \\
\text { STAGE 3: } & \text { without difficulty }\end{array}$ & $\begin{array}{l}\text { no chewing } \\
\text { with difficulty }\end{array}$ \\
\hline $\begin{array}{l}\text { กำจัด kamcal } t \\
\text { STAGE 4: enough food }\end{array}$ & eating up \\
\hline
\end{tabular}

The food is solid.

We put food into the mouth without making noise.

We put food into the mouth slowly, rather than rapidly.

A bite is a tablespoon size, not too small or big.

\section{STAGE 2: CHEWING THE FOOD}

We chew the food.

We chew it slowly, rather than rapidly.

\section{STAGE 3: SWALLOWING THE FOOD}

We swallow the food without difficulty.

\section{STAGE 4: FINISHING}

We have had enough food.

At this point, we can show how nonprototypical cases such as those metonymic and metaphoric expressions discussed above deviate from the norm and how they relate to one another to characterize the eating concept.

\section{Non-prototypical cases}

It appears that the metonymies and metaphors that we have investigated (except the 'getting' words, which I will discuss later), converge on a certain prototypical cognitive model of eating. That is, they are characterized as minimal variants of the model. I will go through the metonymic and metaphoric terms, giving an account of the deviation from the prototype scenario. For each expression, the stage or stages in which the expression deviates are indicated with a prototypical element or elements given above followed by a corresponding nonprototypical element or elements, as illustrated below. 


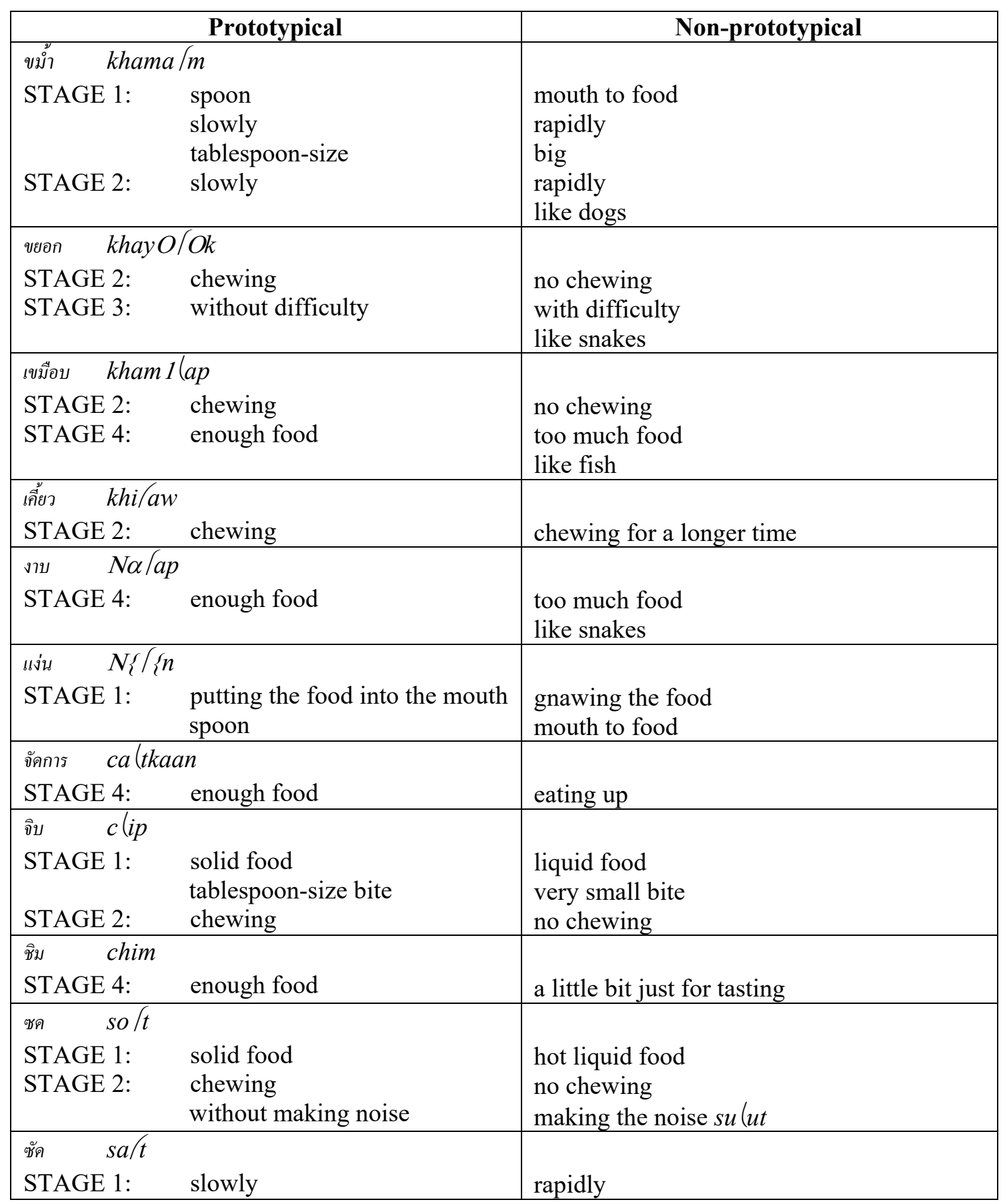




\begin{tabular}{|c|c|c|}
\hline $\begin{array}{l}\text { STAGE 2: } \\
\text { STAGE 4: }\end{array}$ & $\begin{array}{l}\text { slowly } \\
\text { enough food }\end{array}$ & $\begin{array}{l}\text { rapidly } \\
\text { too much food }\end{array}$ \\
\hline โซ้ย so/oy & & \\
\hline STAGE 1: & spoon & chopsticks \\
\hline & Prototypical & Non-prototypical \\
\hline ดื่ม $d 1(1 \mathrm{~m}$ & & \\
\hline $\begin{array}{l}\text { STAGE 1: } \\
\text { STAGE 2: }\end{array}$ & $\begin{array}{l}\text { spoon } \\
\text { solid food } \\
\text { chewing }\end{array}$ & $\begin{array}{l}\text { mouth to food } \\
\text { liquid food } \\
\text { no chewing }\end{array}$ \\
\hline $\begin{array}{l}\text { ดูด } d u(u t \\
\text { STAGE 1: }\end{array}$ & putting food into the mouth & sucking the food \\
\hline $\begin{array}{l}\text { แดก } d\{(\{k \\
\text { STAGE 1: } \\
\text { STAGE 2: } \\
\text { STAGE 4: }\end{array}$ & $\begin{array}{l}\text { slowly } \\
\text { slowly } \\
\text { enough food }\end{array}$ & $\begin{array}{l}\text { rapidly } \\
\text { rapidly } \\
\text { too much food }\end{array}$ \\
\hline $\begin{array}{l}\text { แทะ th }\{/ ? \\
\text { STAGE 1: }\end{array}$ & $\begin{array}{l}\text { putting the food into the mouth } \\
\text { spoon }\end{array}$ & $\begin{array}{l}\text { gnawing the food } \\
\text { mouth to food }\end{array}$ \\
\hline $\begin{array}{l}\text { ฟัด } f a / t \\
\text { STAGE 1: } \\
\text { STAGE 2: } \\
\text { STAGE 4: }\end{array}$ & $\begin{array}{l}\text { slowly } \\
\text { slowly } \\
\text { enough food }\end{array}$ & $\begin{array}{l}\text { rapidly } \\
\text { rapidly } \\
\text { too much food }\end{array}$ \\
\hline $\begin{array}{l}\text { ฟาด } \quad f a / a t \\
\text { STAGE 1: } \\
\text { STAGE 2: } \\
\text { STAGE 4: }\end{array}$ & $\begin{array}{l}\text { slowly } \\
\text { slowly } \\
\text { enough food }\end{array}$ & $\begin{array}{l}\text { rapidly } \\
\text { rapidly } \\
\text { too much food }\end{array}$ \\
\hline $\begin{array}{l}\text { ฟอน } f O O n \\
\text { STAGE 4: }\end{array}$ & enough food & $\begin{array}{l}\text { only some parts of food from } \\
\text { inside }\end{array}$ \\
\hline $\begin{array}{l}\text { เปิบ } \quad p \cong(\cong p \\
\text { STAGE } 1 \text { : }\end{array}$ & spoon & fingers \\
\hline $\begin{array}{l}\text { ล่อ } l O / O \\
\text { STAGE } 4:\end{array}$ & enough food & too much food \\
\hline $\begin{array}{l}\text { ละเลียด lali /at } \\
\text { STAGE 1: } \\
\text { STAGE 2: } \\
\text { STAGE 4: }\end{array}$ & $\begin{array}{l}\text { tablespoon-size bite } \\
\text { slowly } \\
\text { enough food }\end{array}$ & $\begin{array}{l}\text { smaller } \\
\text { too slowly } \\
\text { a little bit of food }\end{array}$ \\
\hline $\begin{array}{l}\text { ลิ้มรส } \quad l i / m r o / \\
\text { STAGE 4: }\end{array}$ & enough food & a little bit just for tasting \\
\hline $\begin{array}{l}\text { เล็ม lem } \\
\text { STAGE 1: } \\
\text { STAGE 2: }\end{array}$ & $\begin{array}{l}\text { tablespoon - size bite } \\
\text { slowly }\end{array}$ & $\begin{array}{l}\text { smaller } \\
\text { too slowly }\end{array}$ \\
\hline
\end{tabular}




\begin{tabular}{|l|l|}
\hline STAGE 4: $\quad$ enough food & a little bit of food \\
\hline
\end{tabular}

\begin{tabular}{|c|c|c|}
\hline & Prototypical & Non-prototypical \\
\hline $\begin{array}{l}\text { เลีย lia } \\
\text { STAGE 1: } \\
\text { STAGE 2: }\end{array}$ & $\begin{array}{l}\text { putting food into the mouth } \\
\text { spoon } \\
\text { chewing }\end{array}$ & $\begin{array}{l}\text { licking the food } \\
\text { mouth to food } \\
\text { no chewing }\end{array}$ \\
\hline $\begin{array}{l}\text { ยัด } y a / t \\
\text { STAGE 1: } \\
\text { STAGE 2: } \\
\text { STAGE 4: }\end{array}$ & $\begin{array}{l}\text { slowly } \\
\text { slowly } \\
\text { enough food }\end{array}$ & $\begin{array}{l}\text { rapidly } \\
\text { rapidly } \\
\text { too much food }\end{array}$ \\
\hline $\begin{array}{l}\text { สวาปาม } \quad s a w a< \\
\text { STAGE 2: }\end{array}$ & $\begin{array}{l}\text { aam } \\
\text { spoon } \\
\text { slowly }\end{array}$ & $\begin{array}{l}\text { fingers } \\
\text { rapidly } \\
\text { like monkeys }\end{array}$ \\
\hline $\begin{array}{ll}\text { อม } & \text { ?оm } \\
\text { STAGE 2: }\end{array}$ & chewing & dissolving \\
\hline $\begin{array}{l}\text { อ้ำ } \quad ? a / m \\
\text { STAGE 1: }\end{array}$ & without making noise & making noise like $/ ? \alpha / \mu /$ \\
\hline $\begin{array}{l}\text { ฮูบ } h u / p \\
\text { STAGE 1: } \\
\text { STAGE 2: }\end{array}$ & $\begin{array}{l}\text { slowly } \\
\text { chewing }\end{array}$ & $\begin{array}{l}\text { rapidly } \\
\text { no chewing } \\
\text { like fish }\end{array}$ \\
\hline
\end{tabular}

The non-prototypical terms cited here are expressions that contain elements (in the right column) deviating from the prototypical scenario (in the left column). They are certainly colorful and give us more information about the prototypical scenario to characterize particular eating actions.

\section{Seeking for the best example}

Apart from the metonymy and metaphor discussed above, there is a small number of eating words which carry every element of the prototypical scenario and do not deviate from the scenario. However, we do not include all of them as prototypical cases.
Lakoff (1987) claims that "prototypes often involve a cluster of conditions". And we find a number of conditions when seeking the prototype of eating terms in Thai other than the idealized cognitive models discussed above. One condition is that the best example of eating is not eating for any specific purpose like 'eating just to get the taste of food'. The words expressing this sense, like chim and li/mro/t (literary style) despite carrying almost all elements of the prototypical scenario are, therefore, not considered prime examples of eating.

Also, a superordinate case like 'consuming' used to present eating via 
terms like bOOripho/ok and selep, should be excluded from our consideration.

Another condition can be formulated: the agents must be ordinary people, not special types of people like the royal family, monks, or infants. The condition is based on the criteria of commonness and markedness. In our everyday life we talk about ordinary people who are the majority more frequently than special individuals, terms for ordinary people therefore are used more frequently and commonly. A set of words which fits this case includes a common term like kin and the polite expressions: ra/pprathan, ra/pthan and thaan. All these eating words carry the prototypical scenario, do not give the sense of any specific purpose, are not superordinate, and assume agents who are ordinary people. They can be differentiated from the other eating words whose agents are those specific social types, as shown.

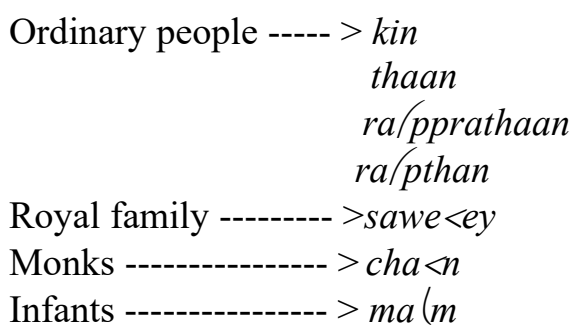

Figure 3: Different Terms for Different Types of People

We might continue to find out which one of the ordinary terms is the best case. Generally, they may be differentiated from one another via degrees of politeness, from the most polite expression to the least polite one, as shown below. (It appears that the more polite word also represents the more formal usage. We, therefore, discuss formality in terms of politeness later.)

\section{ralpprathaan $\rightarrow$ ralpthan $\rightarrow$ thaan $\rightarrow$ kin}

Figure 4: The Most Prototypical Terms ranked from the Most Polite to the Least Polite.

As far as we can tell, the two more polite terms on the left are less common and more marked than the two less polite ones on the right. Regarding unmarkedness, the two terms on the right are fairly comparable candidates for the best example of the eating category so that we might need a statistical finding, rather than simply native speakers' intuition. However, if their original uses can play a role in this issue, the less polite expression should be the best example of the eating category, since it originated from the eating concept, rather than the more polite one, which originated to indicate another event and thus also functions in another category, 'charity'. This is, according to Rosch (1975 and 1978) working on the basic level of category and the notion of prototypicality. In this piece of work, she provides a description for central or prototype membership on the basic of people's judgment of how good an example or how clear a case a member is of a particular category. She proposes that prototype categories are the specific members that contain attributes most representative of items inside the category. The case of kin, therefore, fits this concept well and is more representative of the category than thaan and the other members.

\section{Politeness as a stereotypical model}

According to Lakoff (1987), a stereotypical model is a metonymic model in which a 
good example stands for a category as a whole and serves the purpose of defining cultural expectations. Here, all very prototypical cases, the cases that carry the prototypical scenario, such as kin,

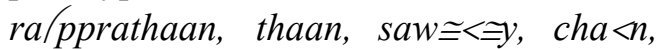
and $m a$ ( $m$, are considered a polite set of eating words. Standing for the eating category as a whole, they reveal the expected eating practice in Thai culture. Politeness, thus, could be said to be an important factor that represents the stereotypical model of eating.

Aside from the prototypical cases, it, however, appears that a number of nonprototypical cases could also convey the polite sense. This is because there is a social importance which can be construed independently from other cognitive models. A way to understand the image of politeness in Thai culture is to understand how an expression or word is used politely or impolitely in certain situations.

As already known among Thai speakers, a word will be selected for use with different listeners generally distinguished by age, as older and younger, social status such as higher status (e.g., parent, bosses, teachers) and lower status (e.g., children, employees, students), and familiarity. Some words, such as those of the prototypical cases, inherently contain the concept of politeness and thus are proper to use with listeners of any age and status. Some words in the non-prototypical cases, e.g., $d\{(\{k, y a / t, l O / O$, sawa $<$ paam, etc., are inherently impolite and cannot be used properly at all, especially with people of older age and higher status. Some words again in the non-prototypical cases, e.g., kamcalt, caltkaan, ?a/m, etc., are unmarked in both senses, but when used with higher age and higher status people, they turn out to be impolite.

\section{Eating as a radial-structure category}

As we have already seen, the less central cases are understood as variants of the more central cases. The metonymic and metaphoric expressions are not understood purely on their own terms; they are comprehended via their relationship to the central model of eating.

The way these variants are extended from the central model is by motivation, rather than being generated by general rules. Therefore, their occurrences are not exactly predictable; they are extended by convention and must be learned one by one.

The eating expressions do not constitute an eating category by means of common properties. The category is structured by chaining, as seen explicitly in the metaphoric cases which constitute the majority of category members. That is, the central member is linked to the noncentral members, which are linked to other members, and so on. For example, 'eating' is linked to 'getting rid of', which is linked to 'hitting'. It is because of chaining that 'hitting' is in the same category as 'eating'. The eating category, thus, is a radial category for this reason. We, therefore, can tentatively provide the structure of the eating category as in the figure below. 


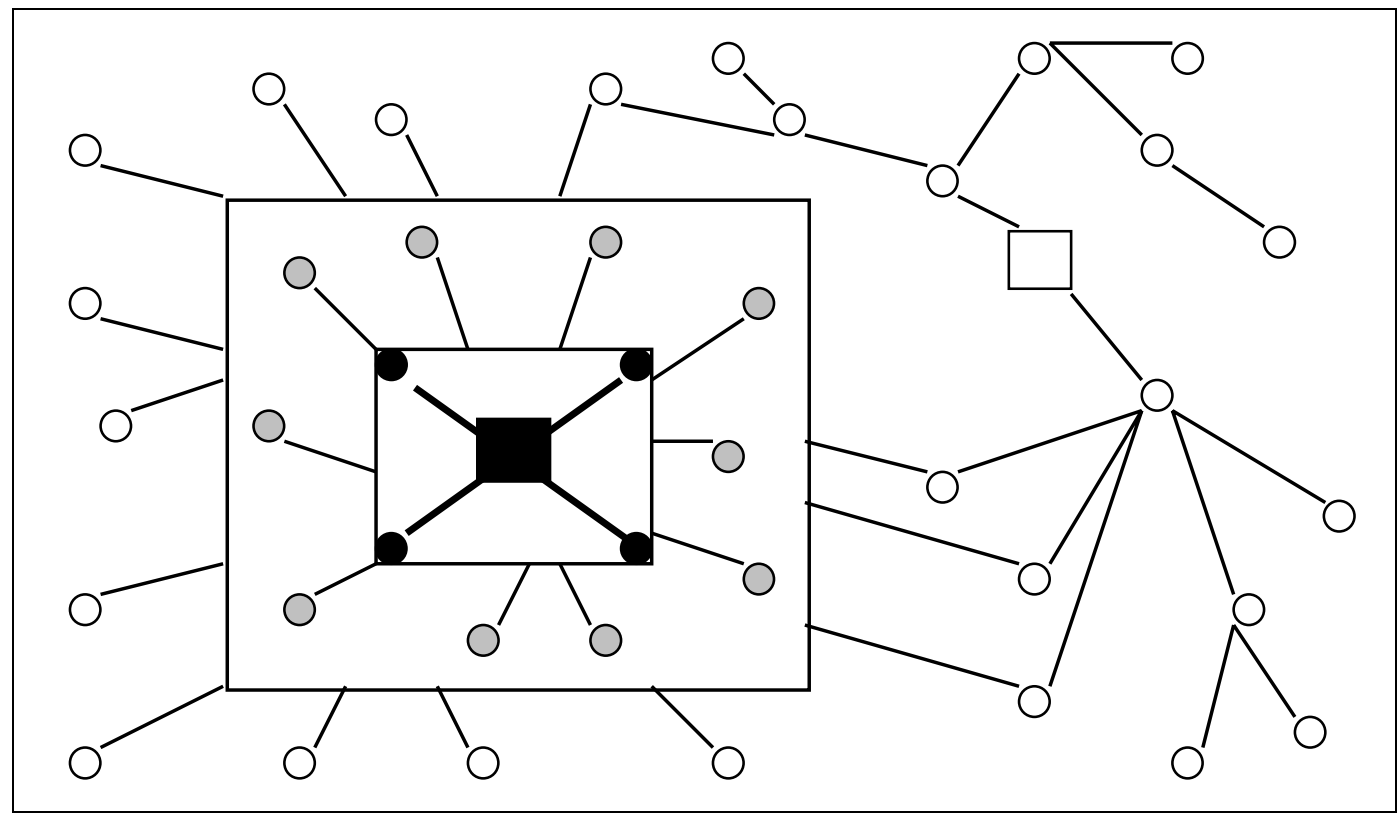

Figure 5: The Eating Category as a

mappings. The link from the prototypical Radial Structure

The squares indicate centers. The circles indicate other members of the category. Degrees of less central members are graded by the grey scale of the items, from black to white, to show the prototype effects. The black square indicates the best example (i.e., kin). The black circles linked to the black square indicate the most prototypical cases. The less dark circles in the bigger square represent the members that are less prototypical (i.e., the other polite words used among ordinary people). The lighter circles in the bigger square further represent the members that are less prototypical (e.g., the words used for special kinds of people). The white (blank) circles represent the other members which are the least prototypical and which are extended from the more prototypical case represented by a white square via metonymic and metaphoric

chain model. The link from the prototypical cases to the metonymic members is more direct. Certain members can be linked to the prototypical cases both directly and by chaining since they are extended from it via the combination of metonymy and metaphor.

\section{Eating category and culture}

So far we have discussed in detail the categorizing nature of the concept studies and its association with Thais' embodied experiences, which give rise to the existence of the wide range of eating terms and cultural explanations associated with the experiences where relevant. However, to support the claim that the category reveals something about the Thai mind, we still need to make clear what makes this a category of the Thai mind, a category that makes sense to Thai 
speakers - that they can learn uniformly and use unconsciously and automatically.

The prototypical scenario illustrates the eating culture of the Thai people. It shows that they have a particular manner of eating at each stage, from putting food into the mouth and chewing to swallowing and finishing it, as discussed above. These experiences give rise to the existence of a number of eating terms differently used with people distinguished by a number of social statuses (like ordinary people, royal family, monks, and infants), familiarity, and situation. The appropriate usages of such terms are also considered polite since they are cultural expectations or what people have already in their mind. This group of eating terms thus not only reveals the Thai eating manner but reflects part of the Thai social structure as well.

The usage of non-prototypical cases, on the contrary, is not generally expected in any formal way and is, thus, considered inappropriate and impolite. These cases are all metonymic and metaphoric terms used to convey semantic elements deviating from the prototypical scenario. They also give us an idea of what Thai people think and of what they do not expect to confront. Such a manner of eating, then, is not considered polite and is used with a negative sense. As is widely known in Thai culture, for instance, animals are disvalued or at least not accorded the same status as humans. Therefore, a human manner of eating that is not expected is sometimes compared with a kind of animal, especially monkeys, dogs, snakes, and fish.

Another salient non-prototypical case deals with rapidity. Eating rapidly is also not expected in any formal situation in
Thai culture. This reveals the cultural fact that doing something at a slow pace is more traditionally acceptable since this manner is believed to show a beautiful and considerate character.

\section{Concluding remarks}

We have illustrated a way to provide an account of Thai eating terms via the prototype theory which, we believe, works well throughout the present paper. This paper provides another piece of evidence for the hypothesis that a language makes use of general cognitive mechanisms called categorization mechanisms. Eating terms in Thai make it worth working with these mechanisms since they offer a good opportunity to investigate the structure of a large and complex/highly patterned "semantic category" and the very notion of it as shown via idealized cognitive models like metonymy and metaphor.

Particularly, the findings reveal that Thai has a particular lexical structure, i.e., radial categories in a chaining model, realized by different sets of words expressing the action of eating. Such words are comparatively numerous and have particular characteristics deviating from the norm, called the prototypical case. Most of them are categorized with the eating concept by use of metonymy and metaphor. The use of these words is, thus, conventional and very culturally dependent: we have to learn about them on a case by case basis.

The paper thus has given detailed answers such as: the reasons why Thai people include each of the eating terms presented here in the eating category, how they make sense of their experience, and how the category is organized, all of which is 
central to understanding how Thai people think and therefore central to an understanding of their mind.

We would hope that the study of Thai eating terms may encourage other lexical investigations in Thai. Here, the analysis comes from an individual native speaker's viewpoint rather than from experimental research. Only a partial survey of the structure of one portion of the Thai lexicon has been conducted. Much work remains to be done not only on the verbal lexicon but on other types of lexical data.

\section{References}

Balkin, J. M. 1998. Cultural software: A theory of ideology. Michigan: Edwards Brothers.

Bolinger, Dwight. 1965. The atomization of meaning. Language. 41, 432-448.

Collins Birmingham University International Language Database. 1992. Collins Cobuild English Language Dictionary. London: HarperCollins.

Haiman, John. 1980. Dictionaries and encyclopedias. Lingua 50, 329-357.

Lakoff, George and Mark Johnson. 1980. Metaphor We Live By. Chicago: University of Chicago Press.

Lakoff, George. 1987. Women, fire, and dangerous things. Chicago: Univerity of Chicago Press.

Rosch, Eleanor. 1975. Cognitive representations of semantic categories. Journal of Experimental Psychology: General.104, 192-233.

Rosch, Eleanor. 1978. Principles of categorization. In Rosch and Lloyd
(Eds.), Cognition and

Categorization, 27-48.

Royal Academy of Thailand. 1999. The standard Thai dictionary.

Bangkok: Nanmi Book

Publication.

Suwilai Premsrirat. 1983. Rueang kham tat nai phasaa Thai (On Cutting Terms in Thai). Phasa Lae Watthanatham, 17-29. 


\section{Index}

\section{Eating Terms}

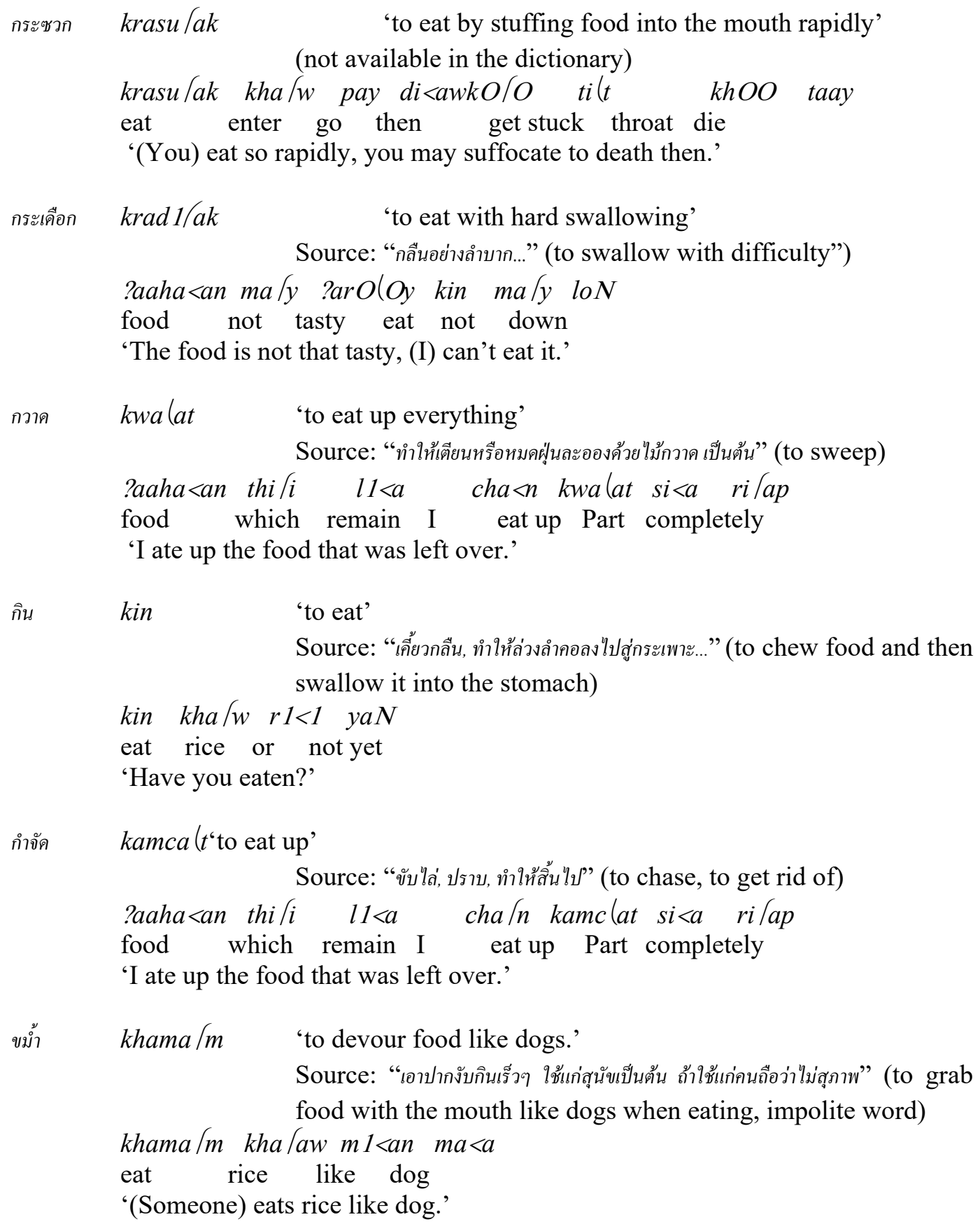



difficultly like snakes'

Source: “ค่อยๆ กลืนอาหารที่คับคอลงไปทีละน้อย" (to swallow a big chunk of food with difficulty)

khayO/Ok kha/w pay da/y thiidiaw tha/N?an

eat into go able a time whole piece

'Someone has eaten up a big chuck of food at a time.'

เขมือบ kham1 lap 'to eat by swallowing a chunk of food like fish'

Source: "กลืนกินอย่างปลา, กินอย่างตะกละ" (to eat like fish, to eat rapidly

kham 1 lap molt lછy and impolitely"

eat all Part

'(Someone) has eaten it up?'

เคี้ยว khi law 'to eat, taking time to chew'

Source: "บดให้แหลกด้วยฟัน" (to chew)

khi /aw mi /aN

eat tea leaves

'Eating tea leaves'

งาบ $\quad \mathrm{Na} / \mathrm{ap}$ 'to eat a lot'

Source: “อ้าปากแล้วหุบ..." (to open the mouth widely and then close it)

Nalap kha/w pay ta/N la<ay chi/n eat enter go up to many piece 'Someone has eaten up many pieces.'

แ่่น $\quad N\{\{n$ 'to eat by biting'

Source: “แยกเขี้ยวจะกัด...” (to bite)

$k h a<w \quad c h O / O p \quad N\{/\{n \quad k r a d u(u k$

he like eat by biting bone

'He likes biting bones.'

จัดการ $c a$ t tkaan 'to eat up'

Source: “สั่งาน, ควบคุมงาน, คำเนินงาน..." (to assign jobs, to

control work, to manage working)

?aaha<an thi $i \quad \quad l 1<a \quad$ cha/n caltkaan si<a rilap

food which remain I eat up Part completely

'I ate up the food that was left over.' 
จิบ $\operatorname{ci}(p \quad$ 'to eat liquid food by sipping'

Source: “ลิ้ม, ดื่มทีละนิด” (to sip)

cilp thii la/? ni/t

sip Clf Part a little bit

'Eat a little bit at a time.'

ฉัน

$\operatorname{ch} a<n \quad$ 'to eat'

Source: “กิน ใช้แก่ภิกษุสามเณร" (to eat, used for monks)

phral? cha<n pheen $l\left\{\int\{w\right.$

monk eat lunch Perf.

'The monk has already had lunch.'

ชิม

chim

'to taste'

Source: “ลองลิ้มรสดูด้วยปลายลิ้น, ทดสองให้รู้รส" (to taste)

lOON chim duu

try taste see

'Try this.'

so/t

'to eat hot liquid food slowly by slurping along with an amount of air and thus making the noise $/ s u / u t /$ '

Source: “กินน้ำร้อน น้ำชา หรือน้ำแกงทีละน้อยๆ มักมีเสียงดังซู้ด" (to drink hot water, hot tea, or curry juice bit by bit, making the sound $s u(u t)$

yala so/t na/am molt

don't eat water get rid of

'Don't eat up its juice.'

ซัด

$s a / t$

'to eat up'

Source: “สาดโดยแรง, เหวี่ยงไปโดยแรง..." (to hit things strongly like waves hit the shore)

mii khO<ONkin tha/wray sa/t ri/ap

have something to eat how much eat up completely

'No matter how much food was there, you ate it up.'

โซ้ย so/oy

'to put food into the mouth by chopsticks'

(not available in the dictionary)

pay so/oy kha/awto/m kan

go eat rice soup together

'Let's go eat rice soup together.' 


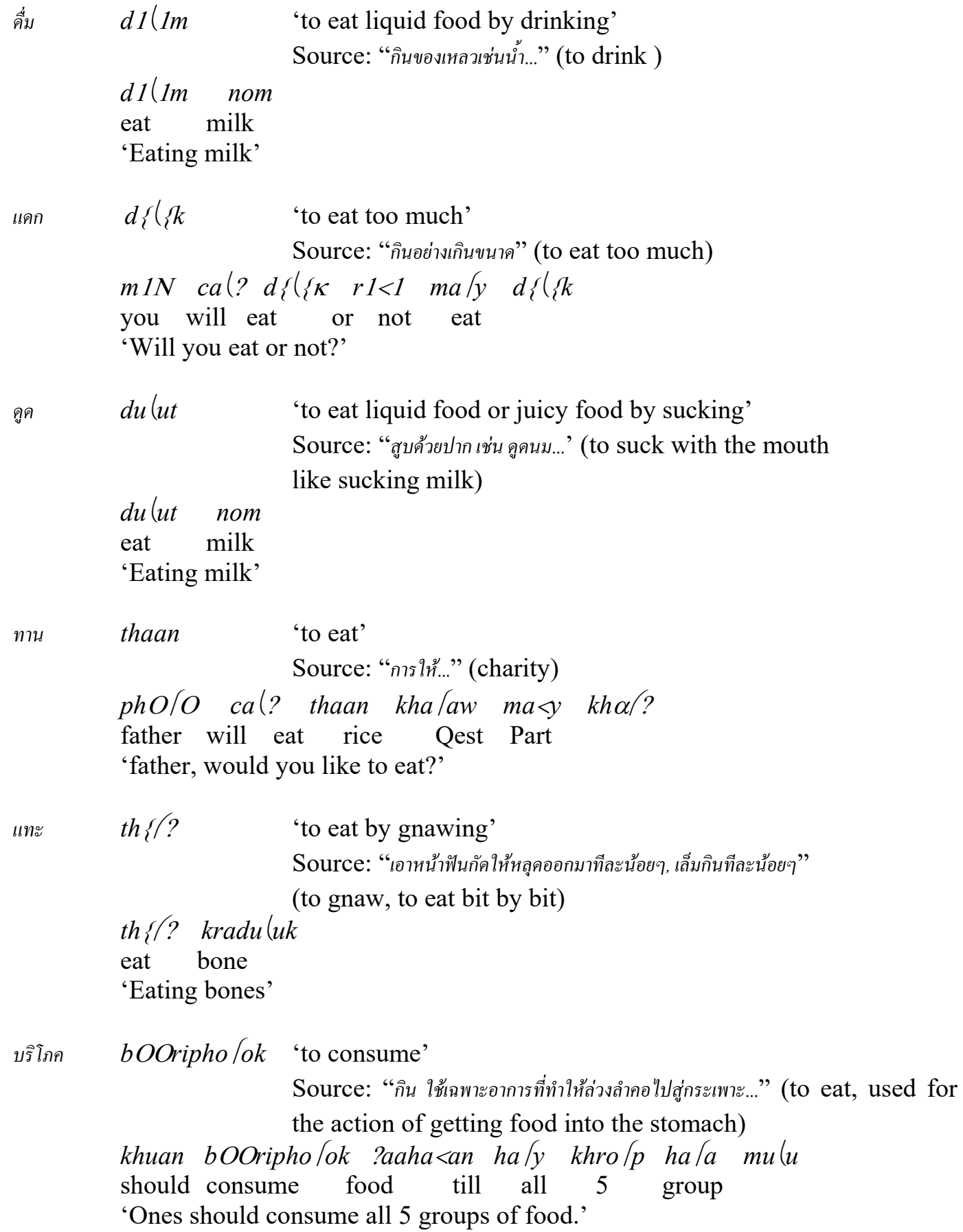


เปิบ $\quad p \cong(\cong p$

'to eat by putting food into the mouth using all five fingers'

Source: “เอานิ้วทั้ง 5 ขยุ้มข้าวเข้าปาก" (to put rice into the mouth using all five fingers)

$p \cong(\cong p \quad$ kha law $t\{l$ lal? kham $s\{$ lin lambalak eat rice each bite very hard

'Eating rice each bite is very hard.'

ฟัด $f a / t$

'to eat up'

Source: “กัดเหวี่ยงหรือสะบัดไปมา..., กระทบ...” (to fight like dogs, to hit)

mii khO<ONkin tha/wray fa/t rilap

have something to eat how much eat up completely

'No matter how much food is there, you ate it up.'

ฟาด $\mathrm{fa} / \mathrm{at}$ 'to eat up'

Source: “หวด, เหวี่ยง...กินอย่างเต็มที่..." (to hit something with a long flexible thing like a whip, to eat as much as one can)

falat khalaw si<a sa<am caan

eat up rice Part 3 plate

'(I) have eaten up 3 plates of rice.'

ฟอน fOOn 'to eat from inside'

Source: “.บ่อน พลอนทั่ว..." (to make thing be in a bad shape)

yala fOOn ?aw t\{l\{ mu<u kin phalk dulay

don't eat take only pork, eat vegetable together.

'Don't eat (by picking) only pork, eat the vegetable too.'

ยัด $y a / t$ 'to eat by stuffing food into the mouth'

Source: “กินอย่างตะกรุมตะกราม" (to eat rapidly and impolitely)

ya/t salapaw kha/w pay ta/N celt lu/uk

eat bun enter go up to 7 Clf

'(Someone) has eaten up 7 buns.'

รับ $\quad \mathrm{ra} / \mathrm{p}$ 'to eat'

Source: “ยื่นมือออกถือเอาสิ่งของที่ผู้อื่นส่งให้.., รับประทาน ก. กิน เช่น รับประทาน อาหาร..." (to obtain, to eat)

phO/O cal? ralp khalaw ?ilik ma<y khal?

father will eat rice more Qest Part

'Father, would you like to eat some more?' 


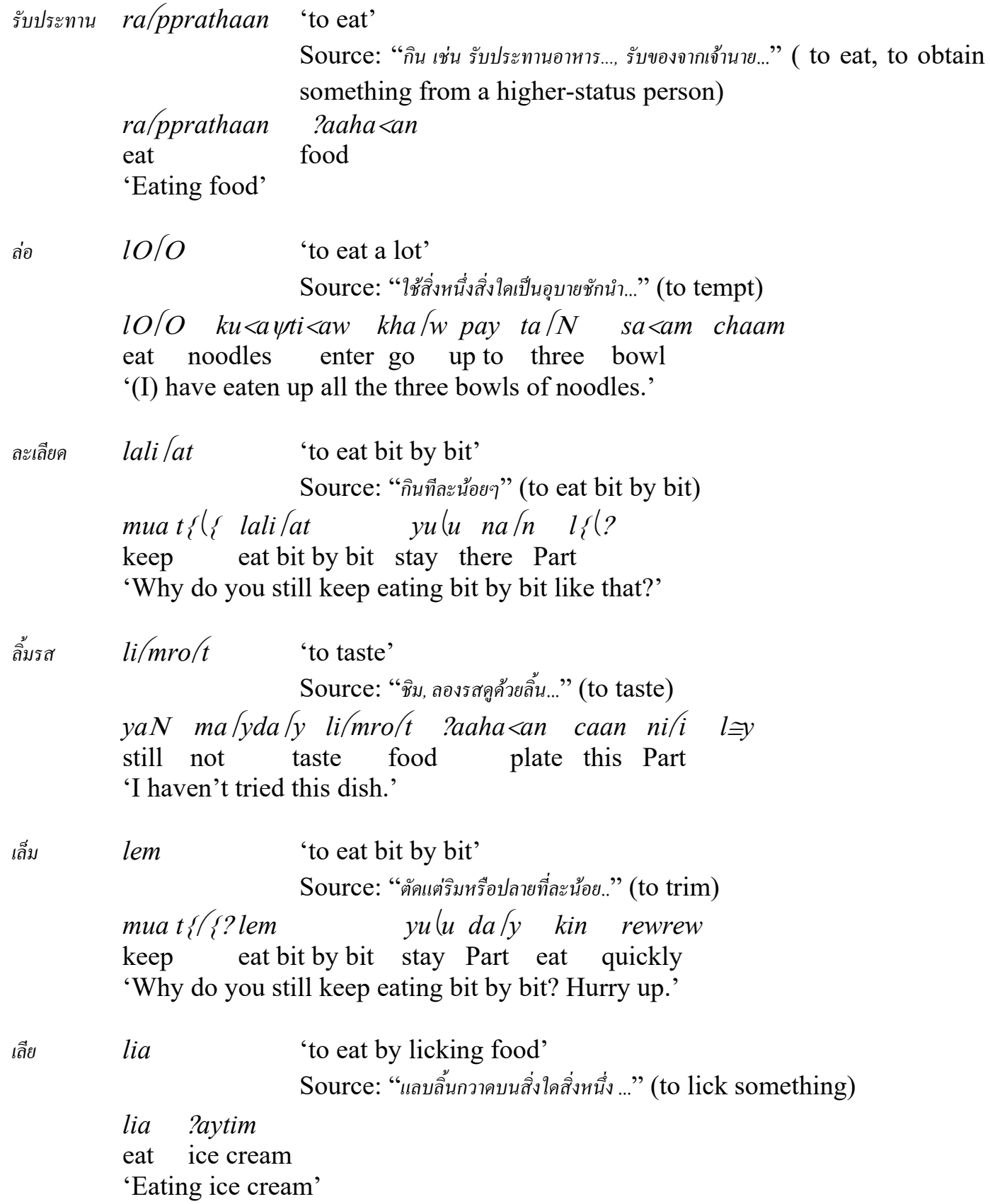




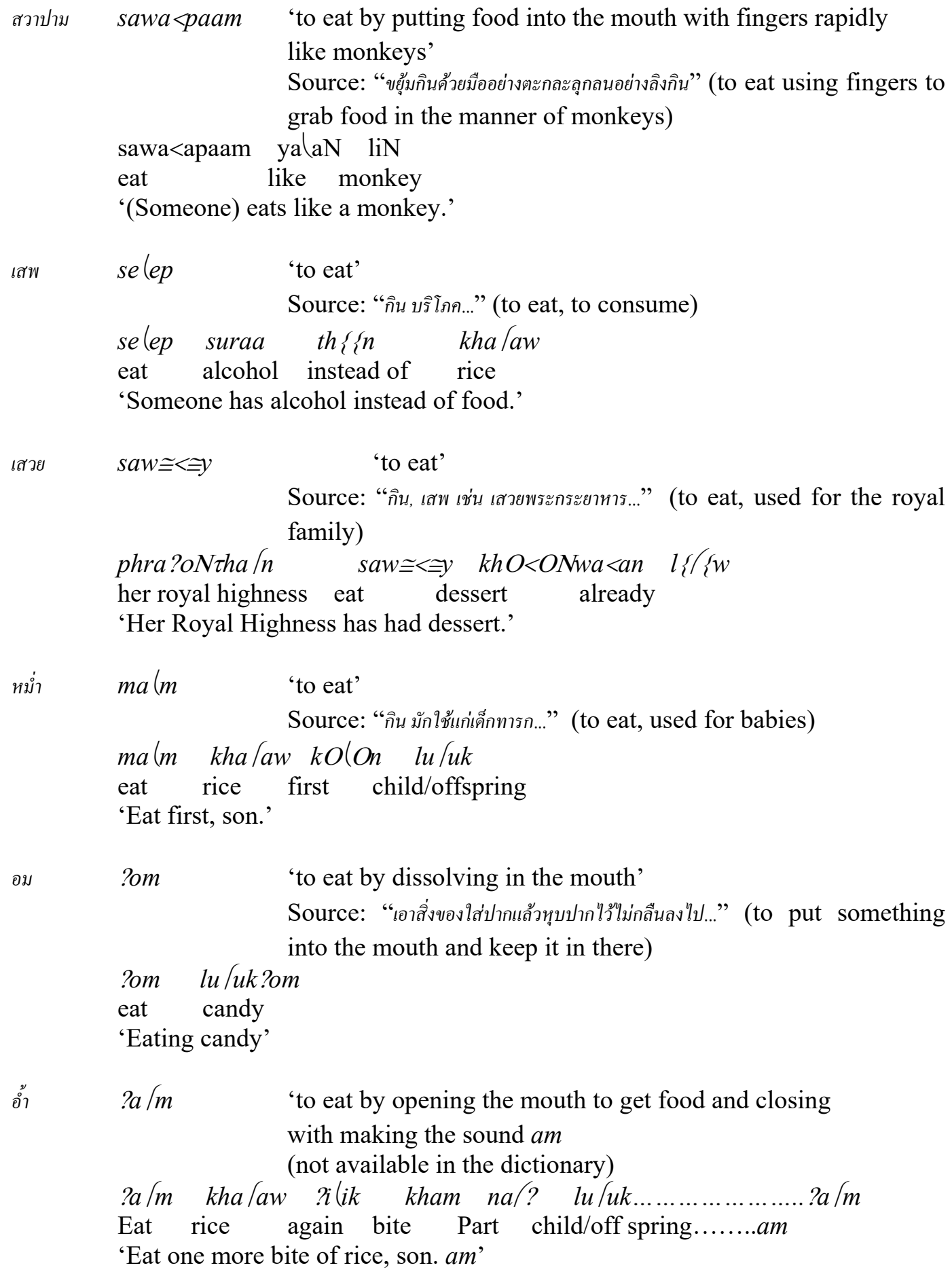


Eating Terms: What the Category Reveals about the Thai Mind

ฮุบ $h u / p$

'to eat by grabbing a chunk of food like fish'

Source: "งับเอาเข้าใว้ในปากเช่น ปลาสุบเหยื่อ" (to grab food with the mouth like fish when grabbing food)

hu/p kha/w pay $l\{/\{w$

eat enter go already

'(Someone) eats a chunk of food rapidly like a fish' 